\title{
An investigation of the clinical experiences of dentists within the national dental foundation training programme in the North West of England
}

\author{
N. O. A. Palmer, ${ }^{* 1}$ J. A. Kirton² and D. Speechley ${ }^{3}$
}

\section{In brief}

Highlights that foundation dentists must satisfactorily complete a learning and development portfolio including a log of clinical experience to work in NHS dental services.
Suggests that NHSBSA data for foundation dentists also gives an indication of the depth and breadth of clinical experience gained during the foundation training year.
Demonstrates that the levels of clinical experience are important if the expected outcomes of foundation training are to be met.

Objective To investigate the clinical experiences of foundation dentists (FDs) in the North West of England. Methods Three research methods were used: a questionnaire completed by FDs at the end of their training; an analysis of the clinical logs of experience recorded in the educational portfolios; and analysis of NHS Business Services Authority (NHSBSA) activity data for the 12 month period of training of FDs. Results A response rate of $100 \%(N=50)$ was achieved for the questionnaire and complete data for 49 of the 50 FDs was available from the NHSBSA and clinical logs in the educational portfolios.

Discussion Trainees were satisfied with the clinical experience and believed their workload and patient mix provided a broad experience of clinical conditions, although $40 \%$ felt there were gaps in their clinical experience. There were wide ranges in the number of individual clinical procedures performed by FDs with some providing very few endodontic treatments, crowns, bridges, metal dentures and fissure sealants. There was a statistically significant difference $(P<0.0005)$ in self- reporting of procedures recorded in the portfolio log when compared to the NHSBSA data. Conclusion The results from this study suggest that there is satisfaction amongst FDs with FT, but there is wide range in the level of clinical experience amongst FDs with some gaps which need to be addressed. In order to provide a consistent, cost effective approach to the delivery of FT changes are required to ensure minimum levels of clinical procedures are achieved during FT. The information collected in the training portfolio must be robust in order to make valid judgements on progress.

\section{Introduction}

The outcome measures required of undergraduate dentists prior to registration in the United Kingdom are based on the General Dental Council's (GDC) Preparing for practice document. ${ }^{1}$ This focuses upon a range of skills, attitudes and behaviours assessed at competency, knowledge, and levels of attainment so that safety, quality care for the patient and current/future health needs are met. The GDC recognises the new graduate as a 'safe

'Research Fellow HEE-North West, Department of Postgraduate Dentistry, Liverpool; ${ }^{2}$ Researcher, Edgehill University,

Ormskirk; ${ }^{3}$ General Dental Practitioner, Liverpool

${ }^{*}$ Correspondence to: N. Palmer

Email: nikolaus.palmer@btinternet.com

Refereed Paper. Accepted 18 July 2016

DOI: 10.1038/sj.bdj.2016.683

${ }^{\odot B r i t i s h}$ Dental Journal 2016; 221: 323-328 beginner'1 well prepared for independent practice who will be expected to develop their knowledge and skills during their career in order to become fully proficient.

The key factor in learning and developing competency skills is work-based clinical exposure in competency-based, outcome focussed training. ${ }^{2}$ Foundation training (FT) consists of a year spent in a training practice gaining valuable clinical experience and developing further competency skills. During this year, trainees, known as foundation dentists (FDs), also undertake an educational day release programme designed to develop clinical skills, knowledge and attitudes required to practice safely. A UK wide curriculum for dental foundation training was established and designed to meet the aims of foundation training which are to produce;

'A competent, caring reflective practitioner able to develop their career in any branch of dentistry to the benefit of patients and also to demonstrate competencies appropriate to independent practice. These competencies are acquired by providing clinical treatment under supervision.' $^{3}$

FT has been mandatory since 1992 for all UK dental graduates who wish to work in the NHS dental services. The NHS requires all dentists to have either completed foundation training, be exempt from foundation training or demonstrate competency through assessments equivalent to foundation training. ${ }^{4} \mathrm{FT}$ in dentistry is comprehensively funded by the Department of Health. In 2013/14 the net total funding allocated for grants, salaries, and services delivered by FDs was approximately $£ 101$ million. In addition to this approximately $£ 13$ m was allocated for delivery of the educational programmes by way of study days and the salaries of foundation training advisers. ${ }^{5}$ 
FT practices are required to have a level of commitment, through a range and supply of patients, to provide a wide range of clinical experience in NHS dentistry to ensure that the competency development and outcomes detailed within the FT curriculum are met. Within the training contract a payment is made for provision of NHS services by the $\mathrm{FD}^{6}$. Since October 2006 NHS dental services in primary care in England are measured by units of dental activity (UDA) which are linked to treatment delivered to patients. In order to provide a broad clinical experience, whole time equivalent FDs are expected to nominally provide 1875 UDAs. ${ }^{7}$

FDs must complete an approved learning and development portfolio. As part of the requirements within the training portfolio trainees have to complete a clinical experience $\log ^{8}$. The importance of case mix (different groups of patients with differing clinical needs) to deliver clinical experience and developing competencies mapped against the FT curriculum cannot be underestimated.

Within medical general practitioner training, research has shown that there are differences in the patient encounters at different training sites. ${ }^{9}$ Factors affecting patient mix in training have also been investigated ${ }^{10}$ and although the extent to which patient mix influences trainees' development is not known, research has shown a positive relationship between patient mix and learning where exposure to patients is combined with supervision. ${ }^{11-13}$ Trainers in
FT are expected to provide trainees with an adequate patient mix that is without educational gaps and sufficiently covering the normal working environment. In FT the only studies that investigated aspects of clinical experience were self-administered questionnaires looking at perceived experiences and confidence levels in a number of clinical areas. ${ }^{14,15}$ Little evidence exists quantifying the clinical experience of trainees and whether this fulfils the aims and requirements of the national dental foundation training programme. The aims therefore of this research were to investigate the clinical experiences of FDs in the northwest of England and highlight gaps, if any, in relation to the clinical experience outcomes defined within the DFT curriculum.

\section{Methods}

The sample consisted of all FDs (50) in Cheshire and Mersey-based training posts in Health Education England (North West) (HEE[NW]) that completed their course in July 2014. Ethical approval was granted by the Edge Hill University Research Ethics Committee and NHS organisational approval was granted by HEE (NW) England.

The study used three investigatory tools. Firstly, a questionnaire to be completed by FDs at the end of their training year, secondly an analysis of the clinical logs of experience recorded in the educational portfolios of the trainees and finally NHSBSA activity data for the 12 month period of the training year.

\section{Questionnaire}

An anonymous questionnaire was designed to explore the FDs' view of their FT. The questionnaire consisted of demographic questions followed by sections exploring clinical experience received during the training year and satisfaction level with their FT.

The questionnaire was informed by the literature and the competencies and expectations of foundation dental curriculum ${ }^{3}$ implementing both open and closed questions including the use of five point Likert scales for the elements of interest. The questionnaire was piloted by all members of the research team and five selected trainers. Comments made through piloting were incorporated into the questionnaires.

The questionnaire was distributed to each FD on the day of their final contact with HEE. The questionnaires were given out in unmarked envelopes with an information sheet which described the study in detail. FDs were asked to complete the short written questionnaire and post it in the allocated box. All questionnaire responses were anonymous and any identifying comments were anonymised.

\section{Training portfolio clinical experience log}

As part of the assessment of progress and activity HEE (NW) had access to the portfolios of trainees. The data from the clinical

\section{Fig. 1 FDs responses to statements regarding their clinical experience in the foundation year}

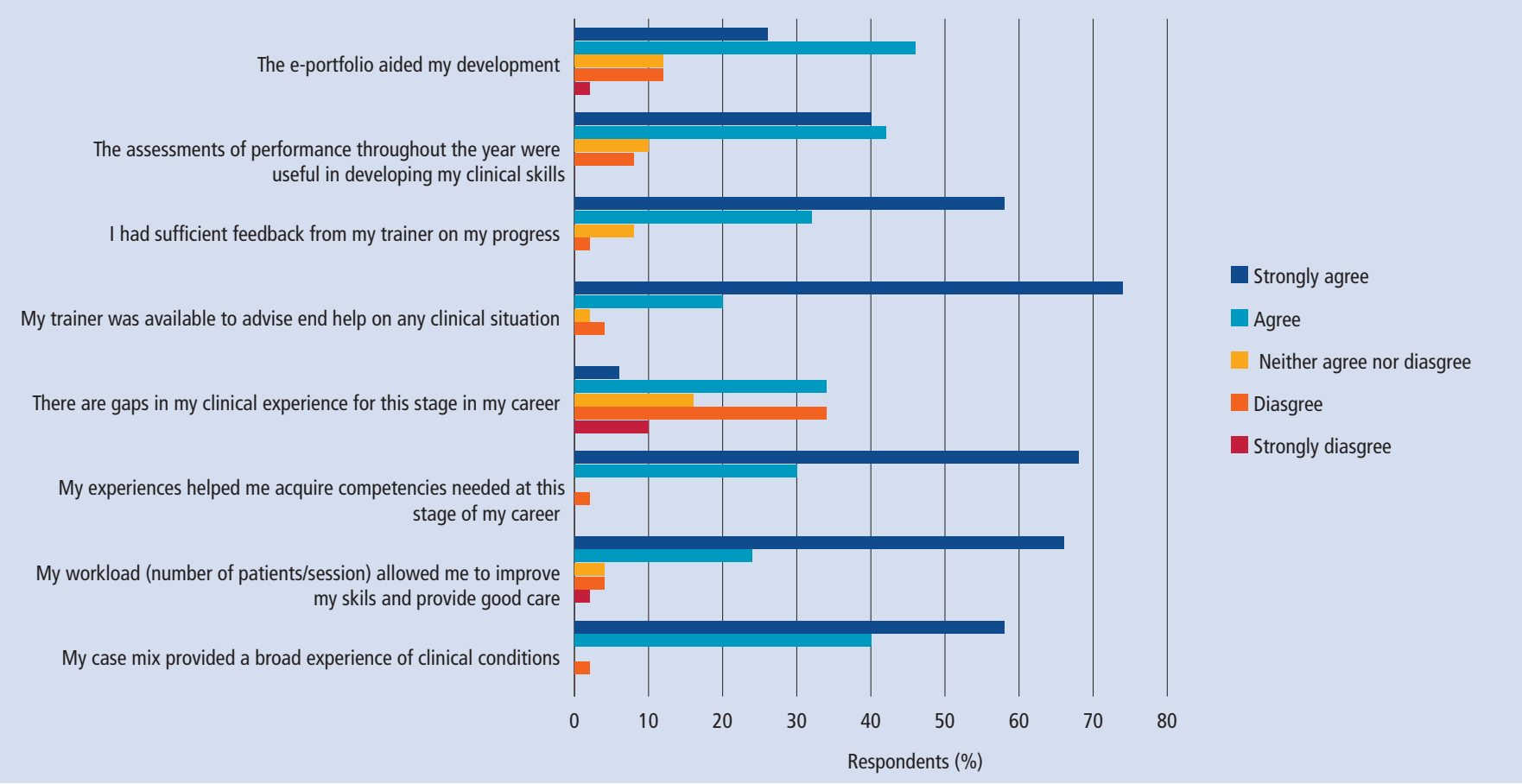


experience logs for each scheme and individual FDs were collected electronically, anonymised, coded and placed in excel database. The data were carefully cross checked to ensure the accuracy of the database.

\section{NHSBSA data}

Trainees' NHS activity data was requested though HEE as the routine publication of 6 and 12 monthly activity reports available to postgraduate deans and trainers had ceased. A list of trainees for the year 2013/14 was provided to the NHSBSA by HEE and the clinical activity reports were requested. The activity reports were coded, anonymised and placed in an excel database and descriptive statistics were produced to represent the data.

\section{Analysis of data}

\section{Questionnaire}

All quantitative data from the questionnaire were input into an Excel database. From this database frequencies were used to examine the responses to all questions and to describe the sample demographics.

\section{Training portfolio clinical log \& NHSBSA data}

The data recorded in the portfolio was placed into IBM SPSS Statistics 22. The data were streamlined by grouping the individual data items into categories, thus making both the analysis and interpretation of the data simpler and more meaningful. For example, whilst endodontic procedures were recorded within the clinical log as incisor/canine endodontic procedures, premolar endodontic procedures and molar endodontic procedures, when carrying out the data analysis they were brought together as endodontic procedures. The final categories analysed after this process were examinations, radiographs, scale and polishing and fluoride varnish, extractions, fillings and sealant restorations, endodontic treatment, crowns/veneers, bridges, fissure sealant, acrylic dentures and metal dentures.

The NHSBSA data were also placed into IBM SPSS Statistics 22. The data were grouped into the same categories, as noted above, following minor adjustments to the data by pooling individual categories.

Frequencies were used to describe and examine the distribution of all variables. Mean scores, ranges and standard deviations were recorded for each of the categories both from the training portfolio clinical logs and the NHSBSA clinical data. A paired sample t-test was used to compare the two sets of information

\section{Results}

A response rate of $100 \%(\mathrm{~N}=50)$ was achieved for the questionnaire and complete data for 49 of the 50 FDs was available from the NHSBSA and the clinical logs of experience recorded in the training portfolios.

\section{Questionnaire}

Sixty two percent (31) of the sample were female. Just fewer than half the respondents (24) qualified at Liverpool University Dental School and there was representation from ten other UK dental schools within the sample. The fifty respondents were based over four geographical schemes within HEE (NW) Cheshire and Mersey.

As can be seen in Figure 1 the majority $(98 \%, 49)$ agreed that their case mix provided a broad experience of clinical conditions with $80 \%$ (40) feeling that their workload allowed them to improve their clinical skills. Forty percent (20) of trainees definitely felt there were gaps in their clinical experience for this stage in their careers and most (90\%) felt that they had sufficient feedback from their trainer on their progress. The majority $(72 \%, 36)$ felt that the assessments of performance throughout the year and the e-portfolio were useful in developing their clinical skills.

In relation to overall satisfaction with the FT year, as shown in Figure 2 the majority were satisfied with the quality of the experience of the post, their training programme director, the clinical supervision provided by the trainer and the quality of teaching provided within the educational programme.

\section{NHSBSA data and training portfolio clinical logs}

The clinical experience of FDs, expressed as the average number of procedures in each treatment area, from the training portfolio clinical log and the NHSBSA data are shown in Table 1. As can be seen there were wide ranges in the number of individual procedures performed within this sample of FDs. Some FDs performed very few endodontic treatments, crowns, bridges and metal dentures and few scale and polishes and fissure sealants. As can also be seen the data recorded in the portfolio clinical log differs from the NHSBSA data (for example, for restorations BSA range 690, portfolio data range 1156)

Fig. 2 Overall satisfaction with DFT expressed as percentages $(N=50)$

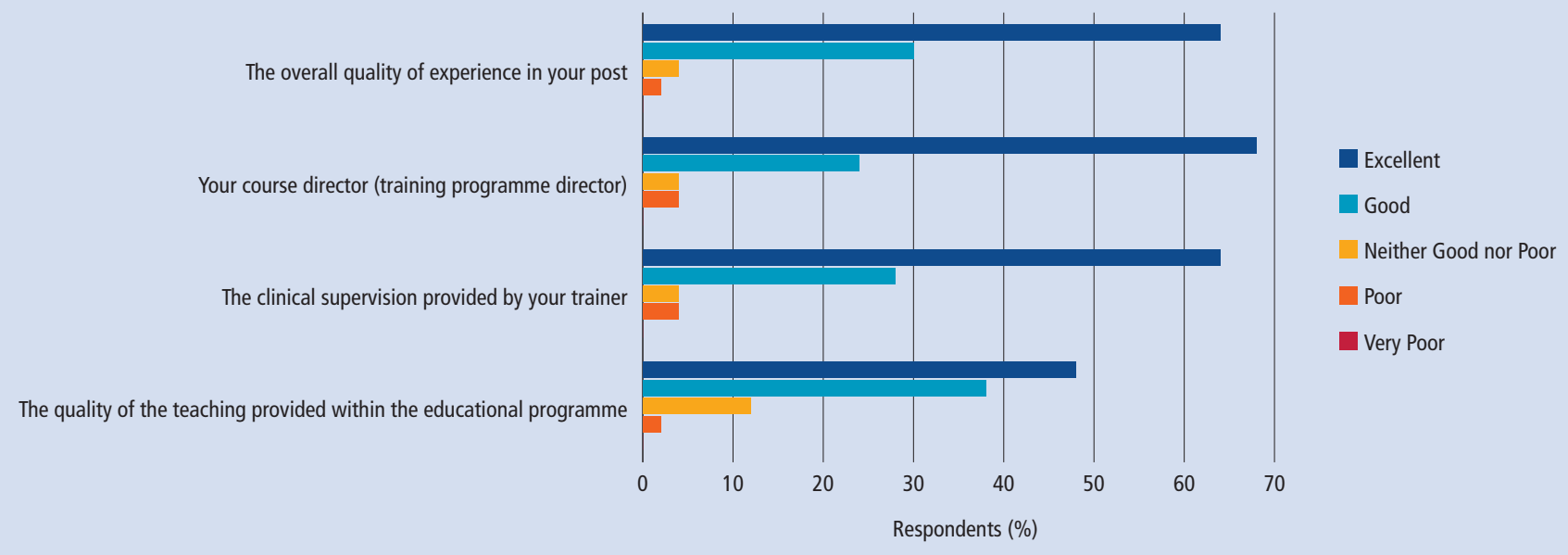


Table 1 Procedures performed by FDs in foundation year recorded by NHSBSA data and in portfolio clinical procedure logs including paired sample t-test results

\begin{tabular}{|c|c|c|c|c|c|c|c|c|c|}
\hline \multicolumn{5}{|l|}{ BSA data } & \multicolumn{4}{|c|}{ Portfolio data } & \multirow[t]{2}{*}{ T-test result } \\
\hline Procedure & Min. & Max. & Mean & SD & Min. & Max. & Mean & SD & \\
\hline Examinations & 219 & 1091 & 537.63 & 210.338 & 229 & 1395 & 591.24 & 221.485 & $\mathrm{~T}(48)=1.883, \mathrm{P}=>0.0005$ \\
\hline Radiographs & 84 & 908 & 468.82 & 188.38 & 308 & 1151 & 685.04 & 197.835 & $\mathrm{~T}(48)=6.616, \mathrm{P}=<.0005$ \\
\hline Scale and polish & 30 & 750 & 214.67 & 126.724 & 42 & 1112 & 308.31 & 190.256 & $T(48)=4.680, P=<0005$ \\
\hline Extraction & 22 & 275 & 115.65 & 57.42 & 51 & 563 & 174.24 & 95.255 & $\mathrm{~T}(48)=6.610, \mathrm{P}=<.0005$ \\
\hline Perm. filling and sealant restoration & 146 & 836 & 402.24 & 139.997 & 313 & 1469 & 671.94 & 234.293 & $T(48)=10.075, P=<.0005$ \\
\hline Endodontic treatment & 2 & 55 & 14.84 & 9.474 & 5 & 130 & 35.02 & 25.255 & $\mathrm{~T}(48)=5.803, \mathrm{P}=<.0005$ \\
\hline Crowns/veneers & 1 & 28 & 11 & 6.308 & 5 & 70 & 22.65 & 15.15 & $\mathrm{~T}(48)=6.381, \mathrm{P}=<.0005$ \\
\hline Bridge & 0 & 11 & 2.1 & 2.201 & 0 & 16 & 4.18 & 3.264 & $\mathrm{~T}(48)=5.399, \mathrm{P}=<.0005$ \\
\hline Fissure sealant & 0 & 66 & 11.9 & 17.573 & 0 & 191 & 45.2 & 48.112 & $\mathrm{~T}(48)=5.134, \mathrm{P}=<.0005$ \\
\hline Acrylic denture & 2 & 99 & 30.2 & 21.075 & 10 & 148 & 46.76 & 31.624 & $\mathrm{~T}(48)=4.849, \mathrm{P}=<0005$ \\
\hline Metal denture & 0 & 14 & 1.31 & 2.551 & 0 & 7 & 1.55 & 1.672 & $T(48)=667, P=>.0005$ \\
\hline
\end{tabular}

The paired sample t-test used to determine whether there was a statistically significant mean difference between the portfolio data and the NHSBSA data showed a statistically significant increase in procedures recorded in the portfolio log when compared to the NHSBSA data. This was noted in all clinical procedure categories except examinations and metal dentures as shown in Table 1.

\section{Patient mix and UDAs}

The average number of patients seen in each age group from the NHSBSA data is shown in Table 2. The greatest number of patients appears to fall within the 25-64 age groups and fewer were seen in the 0-5-year-olds and the over 75-year-old patients. The total number of patients seen during the FT year was highly varied amongst the FDs with a mean of 560.86 (range 293 to 1138; SD 176.83). There was a wide range of the total number of UDAs recorded in the NHSBSA data for the 49 FDs as shown in Figure 3 (minimum 661, maximum 2336 [outlier 2710, mean 1493.05; $\mathrm{SD}=381.29]$ )

\section{Discussion}

This study used a convenience sample of 50 FDs in the HEE (NW) Cheshire and Mersey FT schemes for ease of data collection. It is accepted that the results may show a geographical bias and cannot be extrapolated to the clinical experiences of all FDs in England.

Other studies looking at experiences of FDs relied on self-reporting by way of questionnaire

Table 2 NHSBSA data showing the average number of patients seen in each age group by individual FDs (showing the minimum and maximum number and standard deviation)

\begin{tabular}{l|l|l|l|l}
\hline Age group & Min. & Max. & Mean & SD \\
\hline 0 to 2 & 0 & 31 & 14.49 & 8.2238 \\
\hline 3 to 5 & 7 & 262 & 32.918 & 36.4388 \\
\hline 6 to 12 & 16 & 179 & 62.673 & 32.5547 \\
\hline 13 to 17 & 8 & 88 & 34.633 & 16.4046 \\
\hline 18 to 24 & 16 & 94 & 49.878 & 19.3408 \\
\hline 25 to 34 & 29 & 184 & 83.429 & 34.6019 \\
\hline 35 to 44 & 31 & 143 & 74.143 & 25.3698 \\
\hline 45 to 54 & 32 & 167 & 76.245 & 28.0175 \\
\hline 55 to 64 & 24 & 177 & 59.51 & 27.4356 \\
\hline 65 to 74 & 6 & 143 & 44.224 & 27.1955 \\
\hline 75 or over & 2 & 130 & 30.531 & 24.4763 \\
\hline Total & 293 & 1138 & 560.857 & 176.8343 \\
\hline
\end{tabular}

methodology. ${ }^{14,15}$ This study compared selfreporting by FDs in the FT training portfolio clinical log of procedures completed with data from the NHSBSA. The NHSBSA processes claims for all clinical procedures completed by dentists for payment purposes within the NHS system. FT is funded by the NHS for the NHS at around $£ 115$ million/year and therefore a high quality standardised approach to the training and experience of FDs is important. ${ }^{5}$

Most FT schemes within England are commissioned and run independently, although there is a national recruitment system for trainees ${ }^{16}$ and a nationwide curriculum for FT. ${ }^{3}$ Appointment of trainers and training practices is carried out regionally with differing requirements for these appointments from area to area. Previous research has also shown a diverse use of the assessment tools within the FT portfolio and a clear need for external quality assurance of FT to ensure a consistent standardised quality training programme. ${ }^{17}$

What is clear from this study is most FDs in the study were satisfied with their experience of FT as shown in Figure 2 with a score of between $86 \%$ and $94 \%$ rating the training as good to excellent in the four criteria surveyed. However, the study suggests that there is a variety of experience gained by FDs during the training year within the HEE (NW) Cheshire and Mersey 
schemes. This is evidenced by the number and variety of clinical procedures completed, the patient mix and the number of UDAs delivered as shown in Table 2 and Figure 3. In terms of gaps in clinical experience, $40 \%$ of FDs felt there were gaps in their clinical experience for this stage in their careers.

The study confirmed previous findings of gaps in experience in minor oral surgery and prosthodontics. ${ }^{14,15}$ Lack of oral surgery experience in this study may reflect a lack of confidence or skill within some training practices in this field, or that the remuneration for NHS services by the FD does not adequately justify the complexity or management of possible complications. A recent study showed anticipated complexity, complication and medical complication were found to be the most prevalent reasons for referral. ${ }^{18}$ Very little experience of provision of bridgework in this study may reflect the declining popularity of bridges now that predictable implant placement is available, ${ }^{19}$ lack of appropriate patients or alternatively the unwillingness for training practices to provide such complex and costly treatment for the fixed payment to practices for the provision of NHS services by the FD. FDs are expected to gain clinical experience in these two areas during their training year and the factors preventing this need to be addressed.

The study also showed significant differences in the self-reporting of clinical experience and the NHSBSA data. It is accepted within this study that this may be due in part to the time lag in forwarding of claims by the training practice and processing of claims by the NHSBSA. It is also possible that there was a failure to transmit claims or to accurately record the number and type of procedures within the training portfolio clinical log.

Within the pilot DFT blue guide, a formal process for assessment of FDs is proposed before a Certificate of Satisfactory Completion of FT is provided so that FDs can work as dentists within the NHS. ${ }^{20}$ This process has important implications for dentists and patients. Within this document it also states UDAs should be completed across the range of UDA bands appropriate to demonstrate adequate preparation for NHS dental practice. Also, that the level of UDA delivery should take account of the depth and breadth of clinical experience demonstrated in the clinical activity record within the training portfolio. It also suggests a minimum requirement of clinical procedures, for example, three bridges and two surgical extractions.

It is important therefore that if the training portfolio is to be used as the source of information for assessment of completion for high-stakes decision making, it is reliable, ${ }^{21}$ valid and defensible. A portfolio designed as a programmatic assessment of training with the appropriate information collected can have sufficient validity to assess competency and desired outcomes in training. ${ }^{22}$

\section{Fig. 3 Total number of UDAs recorded by NHSBSA for individual FDs}

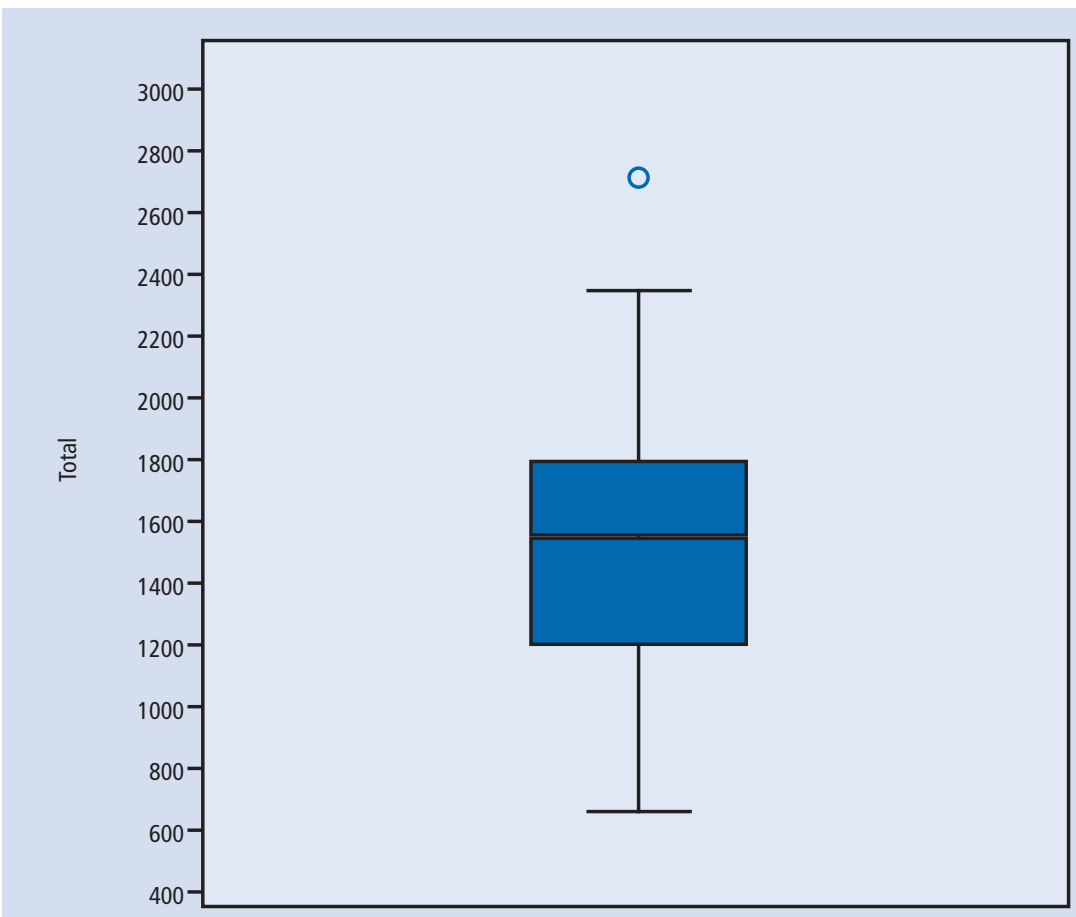

\section{Conclusions}

This study has demonstrated that there is satisfaction amongst FDs with their FT. There is a wide level of clinical experience amongst FDs with gaps which need to be addressed. In order to provide a consistent, cost effective approach to the delivery of FT changes are required to ensure minimum levels of clinical procedures during DFT to deliver the expected outcomes. The information collected in the training portfolio must be robust in order to make valid judgements on progress from safe beginner to independent practitioner.

\section{Acknowledgements}

The authors would like to thank the trainees for taking part in this study, Brian Grieveson, Mike Williams, the LETB and NHSBSA for providing data support.

Declaration of Interests

This study was funded by Health Education England -North West.

1. General Dental Council. Preparing for practice. 2015. Available online at http://www.gdc-uk.org/Aboutus/education/Documents/Preparing\%20for \%20Practice $\% 20$ (revised\%202015).pdf (accessed April 2016).

2. Dornan T, Boshuizen H, King N, Scherpbier A. Experience based learning: a model linking the processes and outcomes of medical students work based learning. Med Educ 2007; 41: 84-91.

3. UK Committee of Postgraduate Deans and Directors. Final draft-Dental foundation training curriculum. 2015 Available online at http://www.copdend.org/content. aspx? Group=foundation\&Page $=$ foundation_programme (accessed April 2016).

4. The National Health Service. Performers Lists, England Regulations. 2013. Online information available at http:// www.legislation.gov.uk/uksi/2013/335/part/1/made (accessed September 2016).

5. Freedom of Information request number151103. People and communications HEE, Cambridge 2015.

6. The National Health Service. The Primary Dental Services Statements of Financial Entitlements (Amendment) Directions. 2015. Available online at https://www. gov.uk/government/uploads/system/uploads/attachment_data/file/450325/Primary_dental_services_directions acc.pdf (accessed April 2016).

7. Implementing local commissioning for primary care dentistry. Gateway reference7620. Fact sheet 6A Dental Vocational Training. Department of Health. Available online at Webarchive.nationalarchives.gov.uk. (accessed April 2016)

8. UK Committee of Postgraduate Deans and Directors. Dental foundation training policy statement. 2011. Online information available at http://www.copdend.org/content. aspx?Group=foundation\&Page=foundation_policy statement (accessed April 2016).

9. Markham F W, Rattner S, Hojat M, Louis D Z, Rabinowitz C, Gonnella J S. Evaluations of medical students' clinical experiences in a family medicine clerkship: differences in patient encounters by disease severity in different clerkship sites. Fam Med 2002; 34: 451-454.

10. de Jong J Visser M R M, Wieringa-de Waard M. Who determines the patient mix of GP trainees? The role of the receptionist. J Fam Pract 2011; 28: 287-293.

11. Van der zwet J, Hanssen V G A, Zwietering P J, Muijtjens A M M, Van der vleuten C P M, Metsemakers J F M et al Workplace learning in general practice: Supervision, patient mix and independence emerge from the black box once again. Med Teach 2010; 32: 294-299.

12. Wimmers P F, Schmidt H G, Splinter T A. Influence of clerkship experiences on clinical competence. Med Educ 2006; 40: 450-458. 
2015. Available online at http://www.copdend.org/content.aspx?Group=foundation\&Page=foundation_dftnationalrecruitment\%202016 (accessed April 2016). ga-de Waard M. A systematic review of the relationship between patient mix and learning in work-based clinical settings. A BEME systematic review. Med Teach 2013; 35: e1181-e1196.

14. Ralph J P, Mercer P E, Bailey H. A comparison of the experiences of newly qualified dentists and vocationa dental practitioners during their first year of general dental practice. Br Dent J 2000; 189: 101-106.

15. Bartlett D W, Coward P Y, Wilson R, Goodsman $D$, Darby J. Experiences and perceptions of vocational training reported by the 1999 cohort of vocational dental practitioners and their trainers in England and Wales. Br Dent J 2001; 191: 265-270.

16. UK Committee of Postgraduate Deans and Directors. Dental Foundation Training (DFT) National Recruitment.
17. Kirton $1 \mathrm{~A}$, Palmer $\mathrm{NOA}$ Grieveson $\mathrm{B}$, Balmer $\mathrm{MC}$ training: a UK study. Effective and useful but do they provide an equitable training experience? Br Dent $J$ 2013: 214: 305-309.

18. Coulthard P, Koron R, Kazakou I, Macfarlane T V. Patterns and appropriateness of referral from general dental practice to specialist oral and maxillofacial surgical services. Br J Oral Maxillofac Surg 2000; 38 320-325.

19. Pjetursson B E, Tan W C, Tan K, Bragger U, Zwahlen M, Lang N P. A systematic review of the survival and complication rates of resin-bonded bridges after A national evaluation of WBAs in foundation dental an observation period of at least 5 years. Clin Oral Implants Res 2008; 19: 131-141.

20. UK Committee of Postgraduate Deans and Directors. Dental Foundation Training Blue Guide for RCP Pilot Year. 2015. Available online at http://www.copdend.org/ content. aspx?Group=foundation\&Page=dentalfoundationtrainingblueguideforrcppilotyear (accessed April 2016)

21. Roberts C, Newble D I, O'Rouke A J. Portfolio-based assessments in medical education: are they valid and reliable for summative purposes? Med Educ 2002; 36: 899-900.

22. Roberts C, Shadbolt N, Clark T, Simpson P. The reliability and validity of a portfolio designed as a programmatic assessment of performance in an integrated clinical placement. BMC Med Educ 2014; 197 